\title{
Transparent organic-inorganic hybrid thin films prepared from acrylic polymer and aqueous monodispersed colloidal silica
}

\author{
Yang-Yen $\mathrm{Yu}^{\mathrm{a}}$, Wen-Chang Chen ${ }^{\mathrm{a}, \mathrm{b}, *}$ \\ ${ }^{a}$ Department of Chemical Engineering, National Taiwan University, Taipei 106, Taiwan \\ ${ }^{\mathrm{b}}$ Institute of Polymer Science and Engineering, National Taiwan University, Taipei 106, Taiwan
}

Received 31 December 2002; received in revised form 17 April 2003; accepted 28 April 2003

\begin{abstract}
Highly transparent hybrid films containing nano-sized silica domain were synthesized from acrylic polymer and aqueous monodispersed colloidal silica (CS) with a coupling agent, 3-(trimethoxysilyl)propyl methacrylate (MSMA). The silica content in the hybrid thin films was varied from 0 to $50 \mathrm{wt} . \%$. The experimental results showed that the silica particle size in the precursor solution and the hybrid films was varied from 20 to $40 \mathrm{~nm}$. It could be controlled by the mole ratio of MSMA to silica. The results of scanning electron microscope (SEM), transmission electron microscope (TEM), and elemental analysis support the above conclusion. The prepared hybrid films showed high film uniformity and optical transparence. The thermal stability of the prepared hybrid films increased with the increasing silica content. The refractive index decreased linearly with the increasing silica fraction in the hybrid films. The experimental results suggest that the hybrid thin films have potential applications as passive films for optical devices.
\end{abstract}

(C) 2003 Elsevier B.V. All rights reserved.

Keywords: Aqueous colloidal silica; Acrylic/silica hybrid; Microstructure; Optical properties

\section{Introduction}

Organic-inorganic hybrid materials have been regarded as a new class of optoelectronic materials [1-3]. They could be applied to various areas of optoelectronics, including protective optical coating [4], high refractive index films [5-8], contact lenses [9], thin film transistor [10], light-emitting diodes [11-13], solar cell [14], optical waveguides materials $[15,16]$, and photochromic materials [17]. The properties of the hybrid materials could be tuned through the functionality or segment size of each component, including thermal, mechanical, electronic, optical, and optoelectronic properties. The flexibility of material design, synthesis, and properties have stimulated extensive research interests.

The hybrid materials of poly(methyl methacrylate) (PMMA)/inorganic oxide has been widely studied [18-29]. The silica network in the hybrid materials was generally prepared from alkoxysilanes [18-23] or colloidal silica (CS) [24-29]. The approach of the colloidal silica provides the advantage of precise control on the size distribution in the hybrid materials. Ford and his coworkers prepared

\footnotetext{
* Corresponding author. Tel.: +886-2-23628398; fax: +886-2-23623040.

E-mail address: chenwc@ms.cc.ntu.edu.tw (W.-C. Chen).
}

PMMA/silica composites for the application of narrow bandwidth optical filters [24-27]. In these studies, colloidal silica with the size larger than $100 \mathrm{~nm}$ was required to diffract the light. However, such hybrid materials were not suitable for highly transparent optical applications. Besides, the thermal stability of PMMA limits the curing temperature of the hybrid materials to be below $100{ }^{\circ} \mathrm{C}$. Hence, the incomplete condensation of $\mathrm{Si}-\mathrm{OH}$ might exist and affect the optical properties. Hence, nanoscale colloidal silica and highly corsslinked acrylic polymers might be necessary for the preparation of the acrylic/silica hybrid optical films. In a previous study, we have successfully prepared the hybrid film from acrylic polymer/nanoscale colloidal silica from acrylic polymer and solvent based colloidal silica [29]. Although the solvent based colloidal silica could be used to prepare hybrid films, the environmental pollution problem and the cost limit their applications. Therefore, the preparation of hybrid films from crosslinkable acrylic polymer and water based colloidal silica-poly(acrylic) hybrid materials is important for their applications.

In this study, poly(acrylic)-silica hybrid thin films were prepared from various acrylic monomers, water based monodispersed colloidal silica and a coupling agent. A mixed solvent of ethylene glycol ethyl ether was used to modify the reaction medium for preventing the phase 
(a)

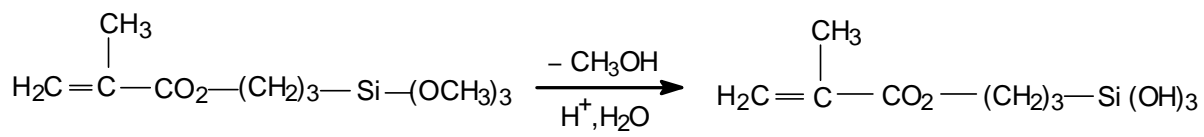

(MSMA)

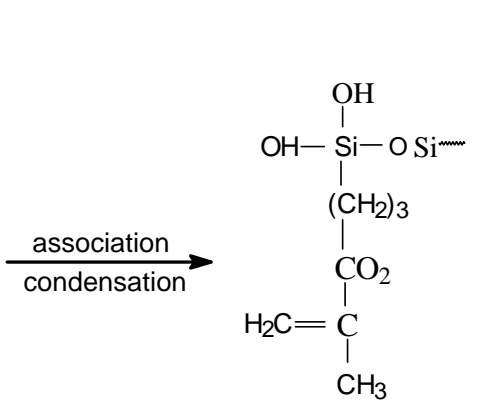

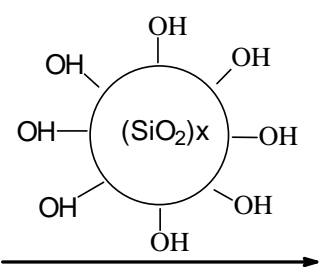

cellosolve, $60^{\circ} \mathrm{C}, 2 \mathrm{hr}$<smiles>C=C(C)C(=O)C[Si](O)(O[SiH2]C)Oc1ccccc1</smiles>

[MSMA-SiO ${ }_{2}$ ]

(b)

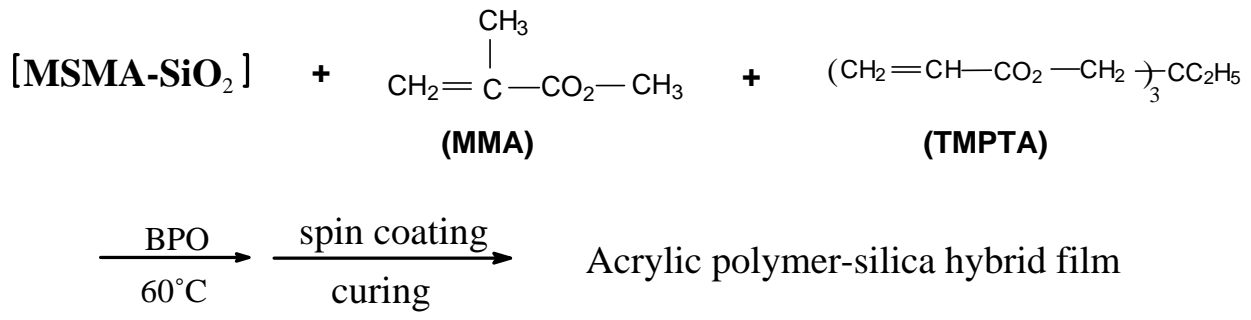

Fig. 1. Reaction scheme for preparing (a) colloidal MSMA-SiO 2 and (b) acrylic polymer-silica hybrid thin films, ST10-ST62.

separation of the prepared hybrid materials. It is because water based colloidal silica was used for the inorganic moiety and acrylic polymer is not soluble in water. The example of preparing the acrylic polymer-silica hybrid films is shown in Fig. 1. 3-(Trimethoxysilyl)propyl methacrylate (MSMA) was hydrolyzed and reacted onto the silica surface to form the MSMA-SiO $(\mathrm{MS})$. Then, it was mixed with the acrylic monomer of methyl methacrylate (MMA) or trimethylolpropane trimethacrylate (TMPTA) and polymerized to form a precursor solution. The precursor solution was then spun coated on the substrate and followed by curing to obtain the hybrid film. The mixture of MMA/TMPTA was used to prevent the fast polymerization if only TMPTA was used for the hybrid materials. The chemical structures, morphology, thermal, mechanical and optical properties of the prepared hybrid thin films were examined. The effects of the MSMA and silica content on the structure and properties of the hybrid thin films were also discussed.

\section{Experimental}

\subsection{Materials}

Methyl methacrylate (99\%, Aldrich), trimethylolpropane trimethacrylate (90\%, Aldrich), 3-(trimethoxysilyl)propyl methacrylate (MSMA, 98\% Aldrich), aqueous colloidal silica (Bayer Taiwan Co., $15 \mathrm{~nm}, 30 \mathrm{wt} . \%, \mathrm{pH}=3.8$ ), ethylene glycol ethyl ether (Cellosolve, Acros), and benzoyl peroxide (BPO, Acros) were used for the synthesis of hybrid thin films.

\subsection{Preparation of colloidal $M S M A-\mathrm{SiO}_{2}$}

The scheme for preparing colloidal MSMA-SiO 2 solution is shown in Fig. 1(a). 3-(Trimethoxysilyl)propyl methacrylate (MSMA), $15 \mathrm{~nm}$ aqueous colloidal silica and ethylene glycol ethyl ether (cellosolve, as a solvent) were mixed at the various compositions as shown in Table 1 . Then, the reaction mixture was poured into a three-necked reactor to proceed the hydrolysis/condensation reaction. The reaction temperature was maintained at $60^{\circ} \mathrm{C}$ and the solution was stirred under a nitrogen flow for $2 \mathrm{~h}$ to obtain the colloidal MSMA- $\mathrm{SiO}_{2}$ solution.

\subsection{Preparation of hybrid acrylic polymer-silica films}

The scheme for preparing hybrid acrylic polymer-silica films is shown in Fig. 1(b). The precursor solution for preparing the hybrid films was obtained according to the composition shown in Table 1. The experimental procedures are 
Table 1

Monomer compositions (wt.\%) for preparing the hybrid thin films HSO-HS50 a and ST0-ST62 ${ }^{\mathrm{a}}$

\begin{tabular}{lcccc}
\hline Sample & Colloidal silica & MSMA & MMA & TMPTA \\
\hline HS0 & 0.00 & 45.00 & 55.00 & - \\
HS10 & 10.00 & 41.00 & 49.00 & - \\
HS20 $^{\mathrm{b}}$ & 20.00 & 36.00 & 44.00 & - \\
HS33 & 33.00 & 30.00 & 37.00 & - \\
HS40 & 40.00 & 27.00 & 33.00 & - \\
HS50 & 50.00 & 23.00 & 27.00 & - \\
ST0 & 20.00 & 36.00 & 44.00 & 0.00 \\
ST10 & 20.00 & 33.00 & 37.00 & 10.00 \\
ST20 & 20.00 & 30.00 & 30.00 & 20.00 \\
ST32 & 20.00 & 27.00 & 21.00 & 32.00 \\
ST42 & 20.00 & 24.00 & 14.00 & 42.00 \\
ST52 & 20.00 & 20.00 & 8.00 & 52.00 \\
ST62 & 20.00 & 18.00 & 0.00 & 62.00
\end{tabular}

a All of polymerization mixtures had the following fixed composition: [MSMA] $/($ acrylic monomer $+[$ MSMA] $)=25 \mathrm{~mol} \%$. The acrylic monomer is MMA for the case of HSO-HS50 and MMA and TMPTA for the case of ST0-ST62; [BPO]/([MMA] + [MSMA] $)=3.75 \mathrm{~mol} \%$.

b The compositions of HS20 and ST0 are the same.

described below. The colloidal MSMA-SiO ${ }_{2}$ obtained in the procedure of Section 2.2 was subsequently mixed with a homogeneous cellosolve solution of the acrylate monomer (MMA or MMA/TMPTA) and the initiator, BPO, to proceed the polymerization reaction under nitrogen purging. The reaction temperature for preparing HS0-HS50 was maintained at $60^{\circ} \mathrm{C}$ for $3 \mathrm{~h}$. For the case of ST0-ST62, the reaction temperature was maintained at $60^{\circ} \mathrm{C}$ and the reaction time was ranged from $3 \mathrm{~h}$ (ST0) to $80 \mathrm{~min}$ (ST62), depending on the TMPTA content. Then, the reaction solution was spin coated on a $0.1524 \mathrm{~m}$ silicon wafer for $20 \mathrm{~s}$ at the speed of $0.319 \mathrm{~m} / \mathrm{s}$. The coated thin film was then cured on a hot plate at $60^{\circ} \mathrm{C}$ for $20 \mathrm{~min}, 80^{\circ} \mathrm{C}$ for $30 \mathrm{~min}$ and $150^{\circ} \mathrm{C}$ for $1.5 \mathrm{~h}$, respectively. For the case of thick films, the coating liquid was concentrated under room temperature to remove the solvent cellosolve using a rotary vacuum evaporator before spin-coating. The curing process was the same as for that of thin films.

\subsection{Characterization}

IR spectra of the prepared thin films were obtained on a $\mathrm{KBr}$ pellet using a Jasco Model FTIR 410 spectrophotometer. The ${ }^{13} \mathrm{C}$ and ${ }^{29} \mathrm{Si}$ NMR spectra of the solid-state hybrids were determined (Bruker, DSX-400 WB) with cross-polarization combined with the magic angle spinning (CP/MAS) technique. The measured condition of the ${ }^{29} \mathrm{Si}$ NMR spectra at $79.4 \mathrm{MHz}$ were as follows: $200-300 \mathrm{mg}$; ${ }^{1} \mathrm{H} 40^{\circ}$ pulse width: $2.5 \mu \mathrm{s}$; spinning frequency: $7 \mathrm{kHz}$; and recycle time: $15 \mathrm{~s}$. The fracture surfaces of hybrid thin films were examined on the Hitachi H-2400, scanning electron microscope (SEM). The particle sizes of the colloidal particle were measured by the Hitachi H-7100 transmission electron microscope (TEM).
The contents of $\mathrm{C}, \mathrm{H}$ and $\mathrm{N}$ in the prepared materials were measured by element analysis using a Neraeus VarioEL-III Element Analyzer. The relative shell thickness of the MSMA and MMA layers on the surface of colloidal silica was estimated from the elemental analysis result, as reported previously [29].

Thermal analyses, thermogravimetric analysis (TGA) and differential scanning calormetry (DSC) were performed under a nitrogen flow using a DuPont Model 951 thermogravimetric analysis and a DuPont Model 910S differential scanning calorimeter at a heating rate of $20^{\circ} \mathrm{C} / \mathrm{min}$ and $10^{\circ} \mathrm{C} / \mathrm{min}$, respectively. The TGA and DSC samples were prepared by spin-coating the precursor solution on a glass substrate, followed by curing at different temperature steps as described in the film preparation. The thermalmechanical properties of the prepared films were tested by a TA 2980 dynamic mechanical analysis (DMA) and a TA 2940 thermo mechanical analysis (TMA). The heating rate was 3 and $10^{\circ} \mathrm{C} / \mathrm{min}$ and the temperature ranged from room temperature to $250^{\circ} \mathrm{C}$ for DMA and TMA, respectively.

The transmittance of the prepared films was measured by using the UV-Vis/NIR spectrophotometer Jasco V-570. A n\&k analyzer (Model 1200, n\&k Technology Inc.) was used to measure the refractive index $(n)$ and the extinction coefficient $(k)$ of the prepared films in the wavelength range of $190-900 \mathrm{~nm}$. The thickness $(h)$ of the prepared films was also determined simultaneously. An atomic force microscope (Digital Instrument Inc., Model DI 5000 AFM) was used to probe the surface morphology of the coated films. The hardness was measured by using a pencil test.

\section{Results and discussion}

\subsection{Analysis of chemical structure}

Fig. 2 illustrates the FTIR spectra of (a) colloidal silica, (b) MSMA-SiO 2 , (c) HS10, (d) HS50 and (e) ST62, respectively. There are two characteristics from the comparison of the spectra. The first comes from the comparison of the $\mathrm{Si}-\mathrm{OH}$ absorption band in the spectra. The $\mathrm{Si}-\mathrm{OH}$ of the pure colloidal silica and MSMA/silica is observed at 963 (Fig. 2(a)) and $916 \mathrm{~cm}^{-1}$ (Fig. 2(b)), respectively, which are similar to those reported in the literature [20,29]. However, the $\mathrm{Si}-\mathrm{OH}$ peak is completely disappeared in the spectra of (c) and (e) but shown in the spectrum of (d). This suggests that the complete condensation of the $\mathrm{Si}-\mathrm{OH}$ bond on the colloidal silica or MSMA-SiO 2 in the cases of (c) and (e). Note that the mole ratio of MSMA to silica was $0.98,0.11$, and 0.22 for the case of (c-e), respectively. The FTIR spectra of the studied HS and ST hybrids show that the $\mathrm{Si}-\mathrm{OH}$ residue could be observed if the mole ratio of the MSMA to silica is smaller than 0.22 . Thus, the incomplete condensation of the $\mathrm{Si}-\mathrm{OH}$ bond in the case of (d) is probably resulted from a high silica content and thus the MSMA could not 


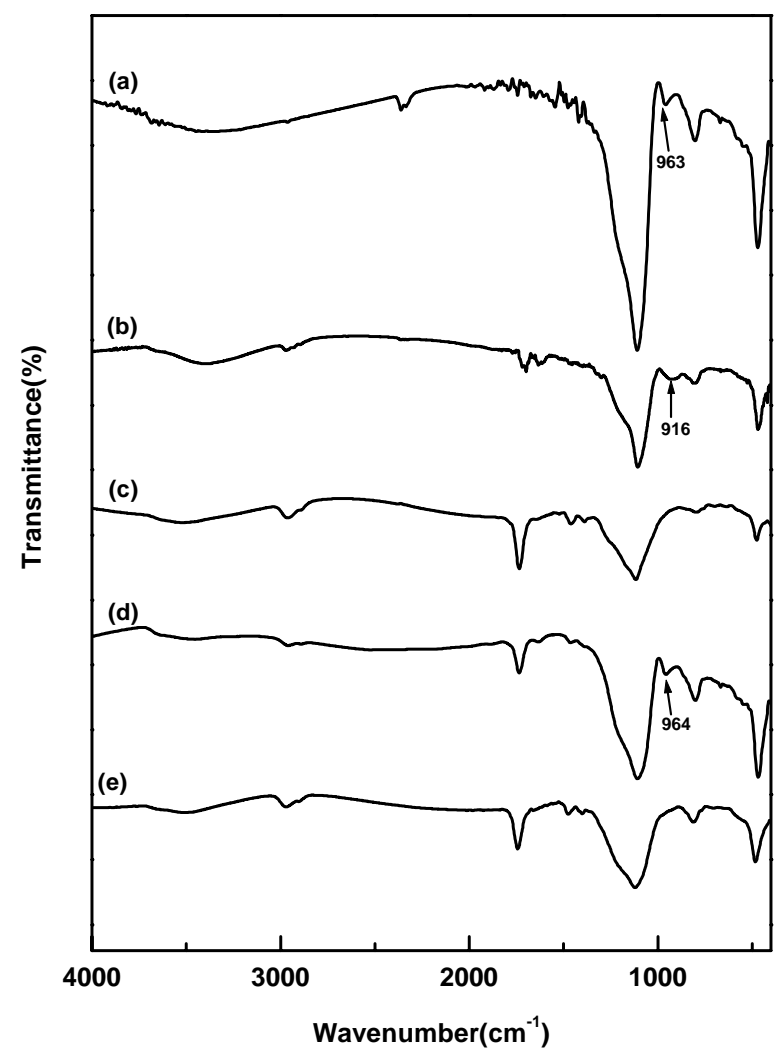

Fig. 2. FT-IR spectra of (a) pure colloidal silica; (b) $\mathrm{MSMA}_{-} \mathrm{SiO}_{2}$; (c) HS10; (d) HS50; and (e) ST62 hybrid polymer films.

react with all of the $\mathrm{Si}-\mathrm{OH}$ bonds on the silica surface. The complete condensation of the $\mathrm{Si}-\mathrm{OH}$ bond on the colloidal silica is important in controlling the size of silica particle for the prepared hybrid film. It is because the residual silanols on the surface of colloidal silica particles increase the probability of further particle growth. The second feature in the comparison of the spectra of (b)-(e) is the absorption band of $\mathrm{C}=\mathrm{C}$ at $1650 \mathrm{~cm}^{-1}$. This band is shown in the spectrum of (b) but disappeared at those of (c)-(e), which suggests the complete polymerization of the acrylic monomers. The absorption bands of $\mathrm{C}-\mathrm{O}-\mathrm{C}$ or $\mathrm{Si}-\mathrm{O}-\mathrm{Si}, \mathrm{Si}-\mathrm{C}, \mathrm{C}=\mathrm{O}, \mathrm{C}-\mathrm{H}$, and O-H bands are observed at 1040-1121, 1265, 1729-1749, 2951 , and $3491-3623 \mathrm{~cm}^{-1}$, respectively. The positions of the absorption bands are similar to those reported in the literatures [19-21,29]. The $\mathrm{Si}-\mathrm{O}-\mathrm{Si}$ band at $1100 \mathrm{~cm}^{-1}$ gradually increases its intensity with increasing the silica content, which indicates the successful incorporation of silica content in the hybrid films.

Fig. 3 illustrates ${ }^{13} \mathrm{C}$ CP/MAS spectrum of the prepared hybrid films: (a) pure colloidal silica, (b) HS10, (c) HS50, (d) ST42 and (e) ST62. The spectrum of the pure colloidal silica shows a strong adsorption peak at $106 \mathrm{ppm}$. The band might be due to the carbon atom of the $\mathrm{Si}-\mathrm{OCH}_{3}$ group, as suggested in the literature $[28,29]$. The result indicates that the $\mathrm{Si}-\mathrm{OCH}_{3}$ residue exists in the pure colloidal silica. For the case of Fig. 3(b), the carbon atoms on the methyl and

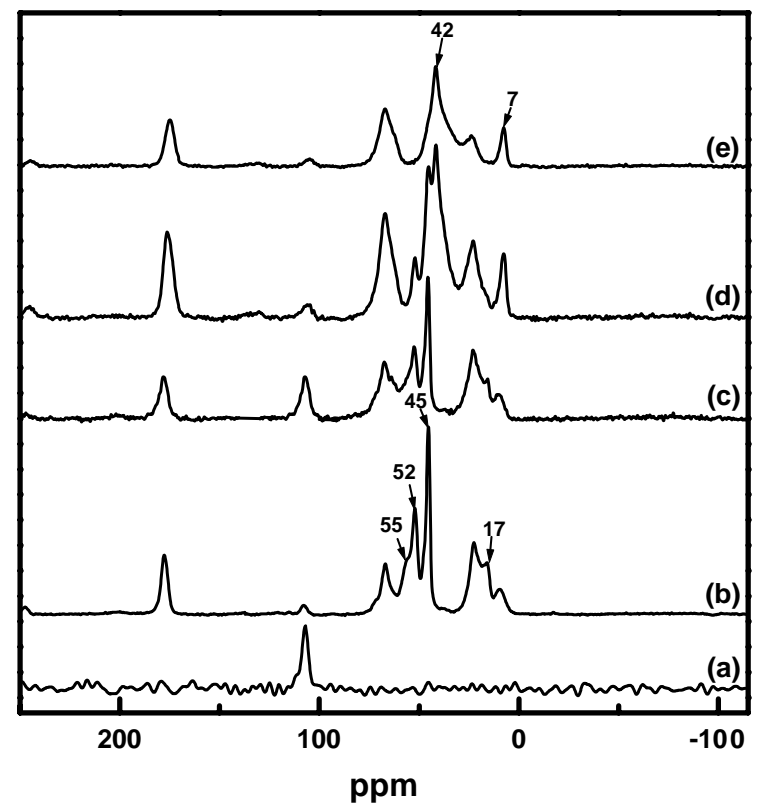

Fig. 3. ${ }^{13} \mathrm{C}$ CPMAS NMR spectra of (a) pure colloidal silica; (b) HS10; (c) HS50; (d) ST42 and (e) ST62.

methylene groups shown are observed at 9, 17, 22, 45, 52, 55, 67, 106 and $177 \mathrm{ppm}$, which are similar to those described in our previous study [29]. The absorption peaks at 17, 45, 52 and $55 \mathrm{ppm}$ are assigned to be the poly(methyl methacrylate) segment [23] while those at 9,22 and $67 \mathrm{ppm}$ are attributed to the MSMA segment [28]. The peak at $106 \mathrm{ppm}$ is assigned to be the $\mathrm{Si}-\mathrm{OCH}_{3}$ residue as suggested by Fig. 3(a). The carbon absorption peaks due to the PMMA segment decreases from Fig. 3(b) and (c) and completely disappeared in the case of Fig. 3(e). For the cases of Fig. 3(d)-(e), the characteristic absorption peaks at 7 and $42 \mathrm{ppm}$ are contributed by the trifunctional acrylate (TMPTA) moiety. The absorption band of the $\mathrm{C}=\mathrm{C}$ bond at $168 \mathrm{ppm}$ is not observed in Fig. 3, which suggests the successful polymerization of the acrylic moiety in the prepared HS and ST hybrid materials. The results indicate that the chemical structure of the prepared hybrid thin films consists with the original design.

The chemical shifts from the ${ }^{29} \mathrm{Si}$ CP/MAS NMR spectra of the prepared hybrid thin films, HS0-HS50, are shown in Table 2. The six chemical shifts at -49.2 to $-50.3,-58.5$ to $-59.5,-66.1$ to $-66.9,-95.1$ to $-97.8,-100.0$ to -103.8 , and -111.2 to $-112.2 \mathrm{ppm}$, are assigned to $T^{1}, T^{2}, T^{3}, Q^{2}$, $Q^{3}$, and $Q^{4}$, respectively. The nomenclatures $T^{i}$ and $Q^{i}$ are taken from the literature [30], where $i$ refers to the number of $\mathrm{Si}-\mathrm{O}-\mathrm{Si}$ groups bonded to the silicon atom of interest. $T^{i}$ and $Q^{i}$ denote species that have one and no organic side groups, respectively. The positions of these peaks are similar to those reported in the literatures [23,28]. The proportion of the $T^{i}, Q^{i}$, and $D_{\mathrm{c}}$ in the hybrid materials was determined by a quantitative analysis based on the peak areas of species, as listed in Table 2. The degree of condensation $\left(D_{\mathrm{c}}\right)$ of the hybrid materials was obtained from the proportions of $T^{i}$ 
Table 2

Chemical shift and relative proportions of $T^{i}$ and $Q^{i}$ species in the prepared hybrids, HS0-HS50 obtained from the ${ }^{29} \mathrm{Si}$ CP/MAS NMR spectra

\begin{tabular}{|c|c|c|c|c|c|c|c|c|c|c|c|c|c|}
\hline \multirow[t]{2}{*}{ No. } & \multicolumn{6}{|c|}{ Chemical shifts (ppm) } & \multicolumn{6}{|c|}{ Proportion (\%) } & \multirow[t]{2}{*}{$D_{\mathrm{c}}(\%)$} \\
\hline & $T^{1}$ & $T^{2}$ & $T^{3}$ & $Q^{2}$ & $Q^{3}$ & $Q^{4}$ & $\overline{T^{1}}$ & $T^{2}$ & $T^{3}$ & $Q^{2}$ & $Q^{3}$ & $Q^{4}$ & \\
\hline HSO & -49.8 & -58.5 & -66.9 & - & - & - & 12.94 & 66.28 & 20.78 & - & - & - & 69.28 \\
\hline HS10 & -50.3 & -59.1 & -66.1 & -97.8 & -103.8 & -112.2 & 10.48 & 40.32 & 20.16 & 4.74 & 3.98 & 20.32 & 76.21 \\
\hline HS20 & -48.4 & -59.2 & -66.7 & -95.8 & -100.9 & -111.2 & 5.94 & 28.63 & 14.00 & 2.14 & 4.32 & 44.92 & 84.33 \\
\hline HS33 & -49.2 & -59.5 & -66.9 & -95.1 & -100.0 & -111.5 & 5.03 & 18.88 & 11.79 & 1.80 & 4.72 & 57.78 & 88.27 \\
\hline HS50 & -50.3 & -58.7 & -67.1 & -96.2 & -103.1 & -111.8 & 2.49 & 10.03 & 8.95 & 1.31 & 9.76 & 67.47 & 91.91 \\
\hline
\end{tabular}

and $Q^{i}$ according to Eq. (1) [23]:

$$
\begin{aligned}
D_{\mathrm{c}}(\%)= & {\left[\frac{T^{1}+2 T^{2}+3 T^{3}}{3}+\frac{Q^{1}+2 Q^{2}+3 Q^{3}+4 Q^{4}}{4}\right] } \\
& \times 100
\end{aligned}
$$

The proportion of the $T^{i}$ species decreases with increasing the silica content of the prepared hybrid films but those of the $Q^{i}$ and $D_{\mathrm{c}}$ species show the opposite trend from Table 2 . The $Q^{3}$ and $Q^{4}$ depend on the $\mathrm{Si}-\mathrm{OH}$ condensation of the silica and thus they increase with increasing the silica content. Similar explanation can be used for the cases of $T^{i}$ and $D_{\mathrm{c}}$.

\subsection{Microstructure analysis}

Fig. 4 illustrates the TEM diagram of the colloidal MSMA/silica solution for the case of HS10. The image of TEM shows that the particle size of colloidal silica after hydrolysis/condensation reaction, $\mathrm{MSMA}-\mathrm{SiO}_{2}$, is about
$15-20 \mathrm{~nm}$, which is approximately similar to the original size $(15 \mathrm{~nm})$ of the pure colloidal silica solution. Similar particle size of the MSMA-SiO 2 was obtained for the cases of the HS20 and HS33. The result suggests no further growth of silica particles if the mole ratio of MSMA to colloidal silica is higher than 0.22 . However, the coagulation of silica particles was observed for the case of HS40 and HS50, which had the particle size of $25-30 \mathrm{~nm}$. Note that the mole ratios of MSMA/silica were 0.16 and 0.11 for HS40 and HS50, respectively. It might not be enough for the encapsulation of the $\mathrm{Si}-\mathrm{OH}$ on the silica surface as described in the FTIR results and thus the growth of silica particles by the $\mathrm{Si}-\mathrm{OH}$ residue was possible. The result indicates that the particle size of silica in the hybrid materials could be effectively controlled for the optimum ratio of MSMA to colloidal silica.

For the cases of the HS10-HS33 and HS40-HS50 hybrid films, the silica domain estimated the SEM results were 20-25 and 30-40 nm, respectively. They could be related to

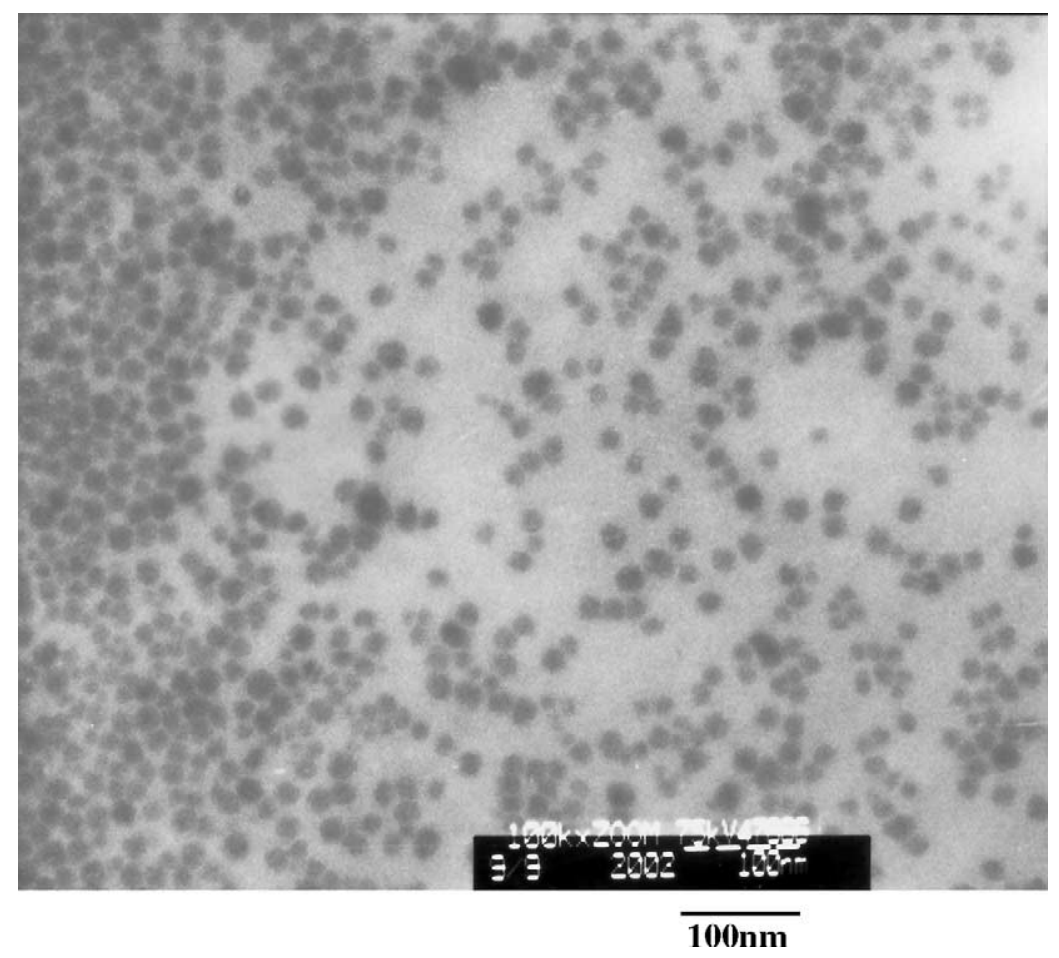

Fig. 4. TEM diagram of colloidal MSMA-SiO 2 for $\mathrm{HS} 10$ (silica size: $15-20 \mathrm{~nm}$ ). 
Table 3

Element analysis of pure silica and the prepared hybrid materials, HS10-HS50, and their corresponding layer thicknesses determined from the carbon content of elemental analysis

\begin{tabular}{lrllll}
\hline Sample & $\mathrm{C}(\%)$ & $\mathrm{H}(\%)$ & $\mathrm{N}(\%)$ & $\Delta h_{\mathrm{MSMA}^{\mathrm{a}}}(\mathrm{nm})$ & $\Delta h_{\mathrm{MMA}}{ }^{\mathrm{a}}(\mathrm{nm})$ \\
\hline $\mathrm{SiO}_{2}$ & 1.80 & 1.55 & 0.05 & - & - \\
$\mathrm{HS} 10$ & 46.64 & 6.42 & 0.03 & 7.53 & 3.89 \\
$\mathrm{HS} 20$ & 39.37 & 5.64 & 0.01 & 4.38 & 2.65 \\
$\mathrm{HS} 33$ & 31.15 & 4.34 & 0.01 & 2.58 & 1.98 \\
$\mathrm{HS} 40$ & 27.09 & 3.70 & 0.01 & 1.99 & 1.69 \\
$\mathrm{HS} 50$ & 20.92 & 3.07 & 0.02 & 1.33 & 1.32 \\
\hline
\end{tabular}

${ }^{a} \Delta h_{\mathrm{MSMA}}$ and $\Delta h_{\mathrm{MMA}}$ are the thickness of the MSMA and MMA layers on the silica surface estimated from the element analysis results.

the size of MSMA-SiO 2 . As suggested by the TEM result, the large MSMA-SiO 2 size was observed for the cases of HS40 and HS50 due to the incomplete coverage of silica particle surface. This explains the large silica domain size of HS40 and HS50. The silica domain size of the ST0-ST62 films are $20-25 \mathrm{~nm}$ because the mole ratio of the MSMA to silica is larger than 0.22 .

The shell thicknesses of the MSMA and MMA layers on the silica surface of the prepared hybrid films, HS0-HS50, are shown in Table 3. They were estimated from the elemental analysis result. The average shell thickness decreases from 7.53 to $1.33 \mathrm{~nm}$ for the MSMA layer and 3.89-1.32 nm for the MMA layer, with the increasing silica content, respectively. The thin shell thickness of the HS40 and HS50 supports the insufficient coverage of MSMA on silica particle suggested from the results of FTIR, TEM and SEM.

The film thickness and surface roughness of the prepared films are listed in Table 4. The film thickness $(h)$, average roughness $\left(R_{\mathrm{a}}\right)$, and mean square roughness $\left(R_{\mathrm{q}}\right)$ of HS10 are $1870,14.3$, and $18.4 \AA$, respectively. The comparison of surface roughness with the film thickness is less than $2.0 \%$, which suggests the excellent surface planarity of the prepared hybrid films. Another trend of surface roughness shown in Table 4, it increases with the silica content due to the growing particle size at a high silica content. For the practical application, film thickness with a few micrometers might be necessary. As shown in the Table 4, film thickness of the prepared hybrid films as thick as $5 \mu \mathrm{m}$ could be obtained. This indicates the potential applications of the prepared hybrid films. There is no direct correlation between the film thicknesses and the silica content because it depends on the spin speed, solid content, and viscosity of the coating solution. However, the film thicknesses of the hybrid films with a high silica contents, HS40-HS50, are lower than others. It is probably due to the low acrylic monomer content or low degree of acrylic polymerization on the silica surface.

\subsection{Thermal analysis}

Fig. 5 shows the TGA curves of PMMA, ST0 (HS20), ST10 and ST62. The order of the thermal decomposition temperature $\left(T_{\mathrm{d}}\right)$ is $\mathrm{ST} 62>\mathrm{ST} 10(\mathrm{HS} 20)>\mathrm{ST} 0>$ PMMA. The thermal decomposition temperature $\left(T_{\mathrm{d}}\right)$ of the prepared hybrid materials is shown in Table 4 . The $T_{\mathrm{d}}$ of the HS and ST hybrid materials is in the range of $279-314^{\circ} \mathrm{C}$ and $292-360^{\circ} \mathrm{C}$, respectively. It increases with increasing silica content or the corsslinking moiety. The thermal stability of the prepared hybrid films are better than the regular used optical polymer, PMMA. The residue at $900{ }^{\circ} \mathrm{C}$ increases with increasing silica content, which suggests the successful incorporation of the silica moiety into the hybrid materials. The higher experimental residue than the theoretical value

Table 4

Properties of the prepared materials

\begin{tabular}{|c|c|c|c|c|c|c|c|c|c|c|c|c|c|}
\hline & HSO & HS10 & HS20 & HS33 & HS40 & HS50 & ST0 & ST10 & ST20 & ST32 & ST42 & ST52 & ST62 \\
\hline$T_{\mathrm{d}}\left({ }^{\circ} \mathrm{C}\right)$ & 279 & 292 & 293 & 303 & 309 & 314 & 292 & 344 & 347 & 350 & 356 & 358 & 360 \\
\hline $900^{\circ} \mathrm{C}$ residue ${ }^{\mathrm{a}}$ & 17.42 & 29.59 & 36.02 & 49.18 & 52.73 & 63.22 & 36.01 & 37.09 & 32.97 & 35.93 & 35.94 & 36.24 & 37.11 \\
\hline $900^{\circ} \mathrm{C}$ residue ${ }^{\mathrm{b}}$ & 9.67 & 18.69 & 27.73 & 39.47 & 45.79 & 54.83 & 27.68 & 27.04 & 26.40 & 25.76 & 25.12 & 24.27 & 23.84 \\
\hline $240^{\circ} \mathrm{C}$ weight loss $(\%)^{\mathrm{c}}$ & 9.03 & 5.21 & 4.19 & 3.92 & 3.62 & 3.53 & 4.19 & 2.05 & 1.90 & 2.00 & 1.61 & 1.59 & 1.42 \\
\hline $260^{\circ} \mathrm{C}$ weight loss $(\%)^{\mathrm{c}}$ & 14.77 & 8.51 & 6.49 & 6.24 & 5.99 & 4.91 & 6.49 & 3.66 & 2.98 & 2.95 & 2.55 & 2.44 & 2.07 \\
\hline$h^{\mathrm{d}}(\AA)$ & 1790 & 1870 & 2450 & 3050 & 2380 & 2320 & 1790 & 1820 & 1850 & 1900 & 2000 & 2020 & 2260 \\
\hline$h^{\mathrm{e}}(\AA)$ & 12040 & 22960 & 51180 & 15850 & 34580 & 11270 & 21510 & 23400 & 24510 & 24000 & 25010 & 26570 & 30010 \\
\hline$R_{\mathrm{a}}{ }^{\mathrm{f}}(\AA)$ & 2.5 & 14.3 & 28.4 & 31.9 & 33.9 & 33.9 & 28.4 & 27.4 & 35.2 & 27.9 & 29.2 & 30.3 & 33.1 \\
\hline$R_{\mathrm{q}}{ }^{\mathrm{f}}(\AA)$ & 3.1 & 18.4 & 35.1 & 37.5 & 42.9 & 43.7 & 36.1 & 35.7 & 36.8 & 36.5 & 36.0 & 40.4 & 42.1 \\
\hline$n_{633 \mathrm{~nm}^{\mathrm{g}}}$ & 1.495 & 1.482 & 1.475 & 1.473 & 1.457 & 1.440 & 1.475 & 1.495 & 1.502 & 1.510 & 1.515 & 1.543 & 1.548 \\
\hline Hardness $^{\text {h }}$ & $\mathrm{HB}$ & $5 \mathrm{H}$ & $5 \mathrm{H}$ & $5 \mathrm{H}$ & $5 \mathrm{H}$ & $5 \mathrm{H}$ & $5 \mathrm{H}$ & $5 \mathrm{H}$ & $5 \mathrm{H}$ & $5 \mathrm{H}$ & $5 \mathrm{H}$ & $5 \mathrm{H}$ & $5 \mathrm{H}$ \\
\hline Hardness $^{\mathrm{i}}$ & $3 \mathrm{H}$ & $9 \mathrm{H}$ & $9 \mathrm{H}$ & $9 \mathrm{H}$ & $9 \mathrm{H}$ & $9 \mathrm{H}$ & $9 \mathrm{H}$ & $9 \mathrm{H}$ & $9 \mathrm{H}$ & $9 \mathrm{H}$ & $9 \mathrm{H}$ & $9 \mathrm{H}$ & $9 \mathrm{H}$ \\
\hline
\end{tabular}

\footnotetext{
${ }^{a}$ Experimental results from TGA.

b Theoretical values based on the assumption that only inorganic moieties are present at $900{ }^{\circ} \mathrm{C}$.

${ }^{c}$ Weight loss from TGA at 240 and $260^{\circ} \mathrm{C}$ isothermal for $1 \mathrm{~h}$

d Thickness of the prepared thin film.

e Thickness of the prepared thick films by concentrating solution.

${ }^{\mathrm{f}} R_{\mathrm{a}}$ and $R_{\mathrm{q}}$ are the average and root mean square roughness of the prepared thin films, respectively.

g $n$ is the refractive index of the prepared thin films.

${ }^{\mathrm{h}}$ Hardness of the prepared thin film.

${ }^{\mathrm{i}}$ Hardness of the prepared thick film.
} 


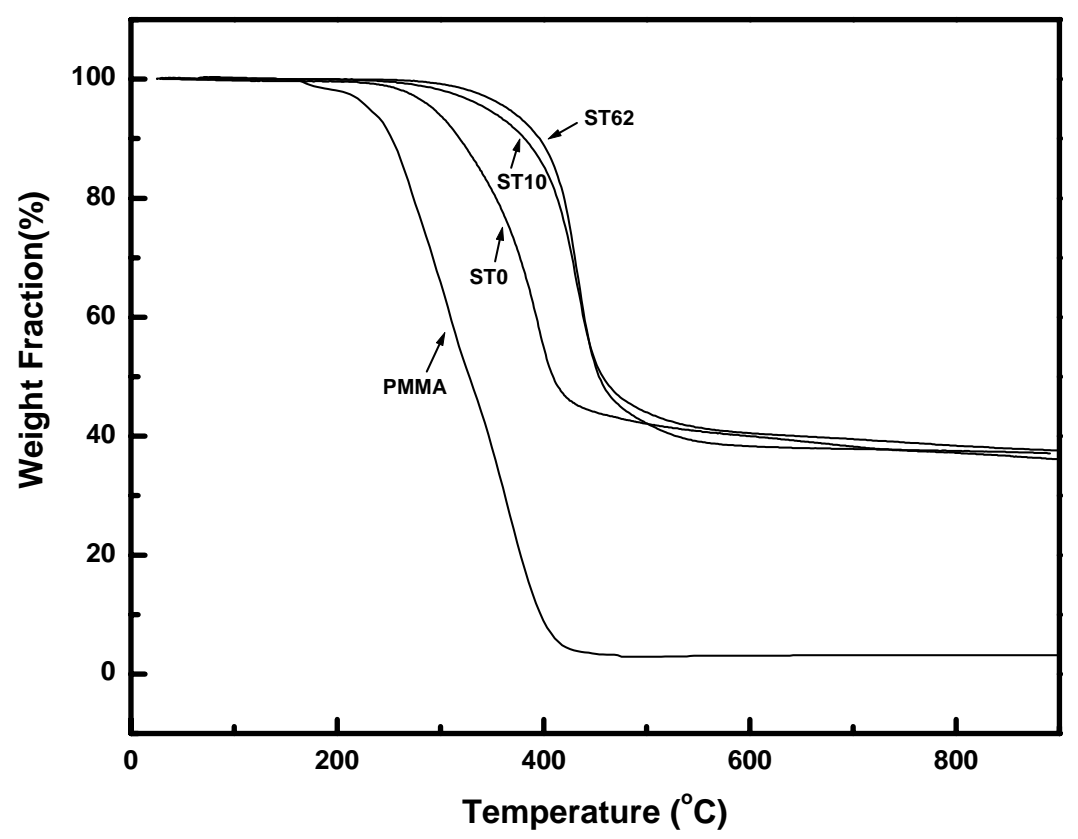

Fig. 5. TGA curves of PMMA, ST0, ST10 and ST62 at a heating rate of $20^{\circ} \mathrm{C} / \mathrm{min}$ under nitrogen flow.

is probably due to the trapping of the polymer moiety in the silica. The black color of the polymer residues after the TGA runs also provides the evidence of the organic moiety has been trapped in the silica matrix. The low weight loss of the prepared hybrid films at 240 and $260{ }^{\circ} \mathrm{C}$ for $1 \mathrm{~h}$ suggests the films could have potential applications as a high temperature coating layer. The DSC analysis was performed on the PMMA and the prepared hybrid materials. Only the PMMA shows a $T_{\mathrm{g}}$ at $125^{\circ} \mathrm{C}$ among the three studied materials. The $T_{\mathrm{g}}$ did not exist in all of the prepared hybrid materials. It suggests the enhancement of thermal stability with incorporating the silica moiety. The thermal transition of the prepared hybrid materials was also studied by DMA and TMA and none of them showed a $T_{\mathrm{g}}$ in the studied materials.

\subsection{Hardness analysis}

The hardness of the prepared hybrid thin films was measured by a pencil test, as shown in Table 4 . The hardness of the HSO hybrid film is $\mathrm{HB}$ and $3 \mathrm{H}$ for the cases of thin film and thick film, respectively. It increases to $5 \mathrm{H}$ (for the

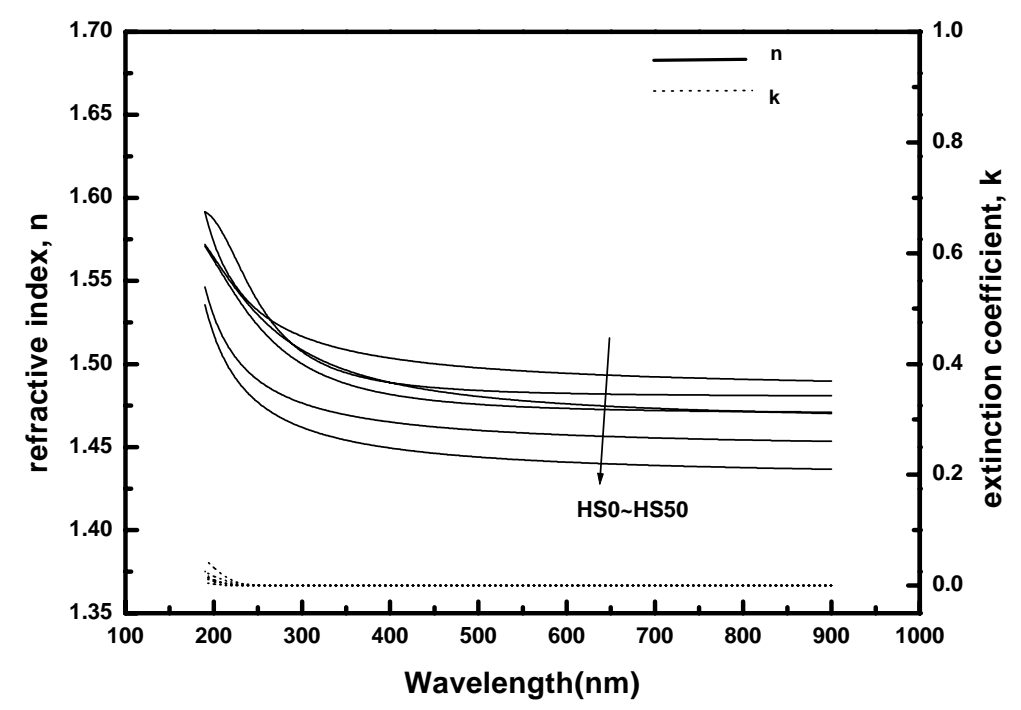

Fig. 6. Variation of refractive index $(n)$ and extinction coefficient $(k)$ of the hybrid films HSO-HS50 in the wavelength range of $190-900 \mathrm{~nm}$. 
thin film case) or $9 \mathrm{H}$ (for the thick film case) with increasing the silica content for the cases of the HS and ST hybrid materials. It suggests that the enhancing of hardness by incorporating the silica moiety in the acrylic polymers.

\subsection{Optical properties}

Fig. 6 illustrates the dispersion of the refractive index $(n)$ and extinction coefficient ( $k$ ) of HSO-HS50 in the wavelength range of 190-900 $\mathrm{nm}$. The refractive index $(n)$ of the prepared hybrid thin films is listed in Table 4. As shown in Table 4, the $n$ at $633 \mathrm{~nm}$ decreases from 1.495 of HS0 to 1.440 of HS50. It is because the smaller refractive index of pure silica than that of the acrylic polymer. The $n$ linearly decreases with increasing the silica content, which are similar to the previous report [29]. The result suggests that the $n$ of the prepared HS hybrid thin films could be tuned through the silica content. On the other hand, the $n$ of the ST hybrid materials increases with increasing the TMTPA content from 1.475 (ST0) to 1.548 (ST62) as shown in Table 4. It is because the higher refractive index of the TMTPA than that of the silica. The extinction coefficients $(k)$ of the films of the HSO-HS50 are almost zero in the wavelength range of $190-900 \mathrm{~nm}$, as shown in Fig. 6. The result suggests that the prepared hybrid thin films have an excellent optical transparency in the UV and visible region. According to the Rayleigh equation, the silica particle with a larger size $(>50 \mathrm{~nm})$ results in a serious light scattering. The particle size of the prepared hybrid films is in the range of $20-40 \mathrm{~nm}$. Therefore, significant scattering loss is avoided. This explains the results of optical transparence shown in Fig. 6.

\section{Conclusions}

Acrylic/silica hybrid thin films containing nano-size silica were successfully prepared from acrylic polymer and aqueous monodispersed colloidal silica with coupling agent. The experimental results showed the silica domain in the hybrid film was varied from 20 to $40 \mathrm{~nm}$ through the mole ratio of MSMA to colloidal silica. The prepared hybrid films from the crosslinked acrylic polymer moiety showed excellent surface planarity, good thermal stability, and hardness in comparison with the PMMA/silica hybrid films. The prepared hybrid films showed a tunable refractive index with the silica fraction in the films. Excellent optical transparence was obtained in the prepared hybrid films. These results show that such hybrid thin films have potential applications as passive films for optical devices.

\section{Acknowledgements}

We thank the National Science Council and Industrial Development Bureau of Taiwan for the financial support of this work.

\section{References}

[1] R.M. Laine, C. Sanchez, C.J. Brinker, E. Giannelis, editors. Organic/Inorganic Hybrid Materials-2000, vol. 628. Materials Research Society, Warrendale, PA, 2000.

[2] C. Sanchez, B. Lebeau, MRS Bull. 26 (2001) 377.

[3] T. Ogoshi, H. Itoh, K.M. Kim, Y. Chujo, Macromolecules 35 (2002) 334.

[4] A. Erashad-Langroudi, C. Mai, G. Vigier, R. Vassoille, J. Appl. Polym. Sci. 65 (1997) 2387.

[5] B. Wang, G.L. Wilkes, J.C. Hedrick, S.C. Liptak, J.E. McGrath, Macromolecules 24 (1991) 3449.

[6] W.C. Chen, S.J. Lee, L.H. Lee, J.L. Lin, J. Mater. Chem. 9 (1999) 2999.

[7] L.H. Lee, W.C. Chen, Chem. Mater. 13 (2001) 137.

[8] C.C. Chang, W.C. Chen, J. Polym. Sci. Polym. Chem. 39 (2001) 3419.

[9] G. Philipp, H. Schmidt, J. Non-Cryst Solids 63 (1984) 283.

[10] C.R. Kagan, D.B. Mitzi, C.D. Dimitrakopoulos, Science 286 (1999) 945.

[11] T.W. Lee, O.O. Park, J. Yoon, J.J. Kim, Adv. Mater. 3 (2001) 211.

[12] W.Y. Huang, S.W. Ho, T.K. Kwei, Y. Okamoto, Appl. Phys. Lett. 80 (2002) 1162.

[13] J. Tang, C. Wang, Y. Wang, J. Sun, B. Yang, J. Mater. Chem. 11 (2001) 1370.

[14] W.U. Huynh, J.J. Dittmer, A.P. Alivisatos, Science 295 (2002) 2425.

[15] C.C. Chang, W.C. Chen, Chem. Mater. 14 (2002) 4242.

[16] C.Z. Xu, L. Eldada, C.J. Wu, R.A. Norwood, L.W. Shacklette, J.T. Yardley, Y. Wei, Chem. Mater. 8 (1996) 2701.

[17] J. Biteau, F. Chaput, K. Lahlil, J.P. Boilot, G.M. Tsivgoulis, J.M. Lehn, B. Darracq, C. Marois, Y. Levy, Chem. Mater. 10 (1998) 1945.

[18] B.K. Coltrain, C.J.T. Landry, J.M. O’Reilly, A.M. Chamberlain, G.A. Rakes, J.S. Sedita, L.W. Kelts, M.R. Landry, V.K. Long, Chem. Mater. 5 (1993) 1445.

[19] W.C. Chen, S.J. Lee, Polymer J. 32 (2000) 67.

[20] C.K. Chan, S.L. Peng, I.M. Chu, S.C. Ni, Polymer 42 (2001) 4189.

[21] Z.H. Huang, K.Y. Qiu, Polymer 38 (1997) 521.

[22] C.K. Chan, I.M. Chu, Polymer 42 (2001) 6823

[23] T.C. Chang, Y.T. Wang, Y.S. Chiu, J. Polym. Sci. Polym. Chem. 38 (2000) 1972.

[24] H.B. Sunkara, J.M. Jethmalani, W.T. Ford, Chem. Mater. 6 (1994) 362.

[25] J.M. Jethmalani, W.T. Ford, Chem. Mater. 8 (1996) 2138.

[26] J.M. Jethmalani, W.T. Ford, G. Beaucage, Langmuir 13 (1997) 3338.

[27] J.M. Jethmalani, H.B. Sunkara, W.T. Ford, S.L. Willoughby, B.J. Ackerson, Langmuir 13 (1997) 2633.

[28] R. Joseph, S. Zhang, W.T. Ford, Macromolecules 29 (1996) 1305.

[29] Y.Y. Yu, C.Y. Chen, W.C. Chen, Polymer 44 (2003) 593.

[30] R.H. Glaser, G.L. Wilkes, Polym. Bull. 19 (1988) 51. 